Gut, 1988, 29, 1342-1348

\title{
HLA-DR expression in human fetal intestinal epithelium
}

\author{
$T$ T MACDONALD, A WEINEL, AND J SPENCER \\ From the Department of Paediatric Gastroenterology, St Bartholomews Hospital, London and Department of \\ Histopathology, University College, London
}

SUMmARY Villus epithelial cells in fetal human small intestine are HLA-DR - until 17 weeks gestation. At 18 weeks HLA-DR begins to be expressed in the epithelial cells, usually at the villus tips. Of 13 specimens examined between 18 and 22 weeks gestation, two were HLD-DR-, seven had HLA-DR expressed only at the villus tips and in four most of the villus epithelial cells were HLA-DR + . The epithelium overlying the Peyer's patches in fetal intestine was also HLA-DR+. $T$ cells in explant cultures of fetal intestine were activated in situ using pokeweed mitogen. The local cell mediated immune reaction increased expression of HLA-DR on the villus and crypt epithelial cells. Organ culture supernatants from explants treated with pokeweed mitogen induced HLA-DR expression on the HT-29 epithelial cell line; an effect inhibited by antibody against human interferon gamma.

In normal adult human small intestinal epithelium, HLA-DR molecules are present in the villus enterocytes and the epithelial cells overlying the Peyer's patches. ${ }^{1-3}$ Epithelial cells in the crypts of Lieberkühn are HLA-DR -. In epithelium which abuts Peyer's patches the cells which overlie the lymphoid follicle and immediately adjacent crypt cells are HLA-DR+ whereas epithelial cells on the other side of the crypt (which are derived from the same enteroblastic progenitor cells) are HLA-DR.$-^{3}$ This clearly implies that local immune microenvironment plays a role in whether an epithelial cell expresses HLA-DR. HLA-DR + epithelial cells may present antigen to mucosal $\mathrm{T}_{\text {cells }}{ }^{4}$ and thus may also play a role in the onset and perpetuation of chronic inflammation in the gut such as coeliac disease or inflammatory bowel disease where HLA-DR expression by enterocytes is increased. ${ }^{56}$ We have previously shown that fetal human small intestine becomes infiltrated with lymphocytes from 14 weeks gestation and by 19 weeks lymphoid aggregates (Peyer's patches) containing $T$ and $B$ cell zones can be clearly identified. ${ }^{*}$ We have now investigated the development of HLA-DR expression in villus epithelial cells in fetal

Address for correspondence: Dr Thomas T MacDonald. Department of Paediatric Gastroenterology, Dominion House, St Bartholomews Hospital, London ECIA 7BE.

Received for publication 30 June 1988 . human intestine. We have also investigated whether the lymphoepithelium overlying fetal Peyer's patches expresses HLA-DR.

We have also recently described a new organ culture system in which a severe enteropathy can be produced in small explants of fetal human small intestine in vitro by directly activating mucosal $\mathrm{T}$ cells with mitogens or anti-CD3 monoclonal antibodies." We have thus used the organ culture model of $T$ cellmediated enteropathy to determine if we can induce HLA-DR expression in villus enterocytes by a defined local cell mediated immune response.

\section{Methods}

FETAL SMALL INTESTINE

This was obtained from therapeutic abortions by curettage. Fetal age was determined by foot measurement ${ }^{\text {"I }}$ and in some cases by ultrasound.

ORGAN CULTURE OF FETAL SMALL INTESTINE Small intestine was dissected into $2-3 \mathrm{~mm}$ square explants and cultured in serum free CMRL-1066 media, modified according to Autrup et al," as described elsewhere. '2 There were five explants per culture dish. $T$ cells in the lamina propria of the explants were activated by the addition of $15 \mu \mathrm{g} / \mathrm{ml}$ pokeweed mitogen (PWM, Sigma Chemical Co, 
Poole, Dorset) at the initiation of the cultures. In some experiments cyclosporin A (Sandoz) was used to inhibit the PWM induced $\mathrm{T}$ cell activation.

IMMUNOHISTOCHEMICAL DETECTION OF

HLR-DR IN FETAL GUT EPITHELIAL CELLS

After three to four days in culture the explants were snap frozen in liquid nitrogen and stored frozen at $-70^{\circ} \mathrm{C}$ for further analysis. Frozen sections of the explants were cut and stained by the immunoperoxidase technique using the monoclonal antiHLA-DR, 1B5 (from Dr E Adams, Imperial Cancer Research Fund, Lincoln's Inn Fields, London) or a commercial anti-HLA-DR (anti- $\beta$ chain, Dako Ltd, High Wycombe, Bucks) as described elsewhere..$^{13}$ The organ culture supernatant was aliquoted and stored at $-20^{\circ} \mathrm{C}$.

INDUCTION OF HLA-DR ON HT- 29 CELLS WITH ORGAN CULTURE SUPERNATANTS

The transformed intestinal epithelial cell line HT-29 was obtained from the European Collection of Animal Cell Cultures, Porton Down, and was grown and passaged in RPMI-1640 culture medium containing $10 \%$ fetal calf serum. Fifty thousand HT-29 cells were added to microculture wells on plastic slides (Labtech tissue culture chamber slides, Miles Laboratories, Napierville, Illinois, USA) in a volume of $0.2 \mathrm{ml}$ and allowed to adhere overnight. The next day the adherent cells were washed and were treated with dilutions of organ culture supernatants or recombinant gamma interferon (a gift from Dr Allan Morris, University of Warwick). Twenty four hours later the cells were washed and stained immunohistochemically with anti-HLA-DR. Each culture supernatant was tested in duplicate. The person reading the slides was unaware of the origin of the supernatant added to the HT-29 cells. The percentage cells expressing HLA-DR was taken as the mean of the duplicate tests of each supernatant dilution.

Sheep anti-recombinant interferon gamma (a gift from Dr A Meager, British Institute for Biological Standards, Potters Bar, Herts) was added to some of the wells.

\section{Results}

EXPRESSION OFHLA-DR ON FETAL GUT

EPITHELIAL CELLS BETWEEN 11 AND 22 WEEKS GESTATION

We have previously shown using a small sample of fetal ileum that HLA-DR does not appear to be expressed in intestinal epithelial cells until 19 weeks gestation, although most of the cells in the underlying lamina propria are strongly HLA-DR + from 11 weeks gestation. ${ }^{14}$ We have now investigated 20
Table 1 Development of HLA-DR expression in epithelial cells in fetal human small intestine

\begin{tabular}{lll}
\hline Age of specimen & Spec no & Villus epithelial HLA-DR expression \\
\hline 11 weeks & 1 & Negative \\
14 weeks & 1 & Negative \\
& 2 & Negative \\
16 weeks & 1 & Negative \\
& 2 & Negative \\
17 weeks & 1 & Negative \\
& 2 & Negative \\
18 weeks & 1 & Negative \\
& 2 & Weakly+, villus tips \\
19 weeks & 3 & Weakly+, most of villus \\
20 weeks & 1 & Weakly+, villus tips \\
& 1 & Weakly+, villus tips \\
& 2 & Weakly+, villus tips \\
21 weeks & 3 & Strongly+, most of villus \\
& 1 & Weakly+, villus tips \\
22 weeks & 2 & Weakly+, villus tips \\
& 1 & Strongly+, most of villus \\
& 2 & Strongly+, most of villus \\
& 3 & Weakly+, villus tips \\
& 4 & Negative \\
\hline
\end{tabular}

All the specimens were kept at $4^{\circ} \mathrm{C}$ and snap frozen in liquid nitrogen within two hours of being removed from the aborted fetus. Samples of ileum and jejunum were obtained. No variation in epithelial HLA-DR expression along the length of the gut was observed. Specimens negative in the ileum were negative in the jejunum and likewise specimens positive in the ileum were also positive in the jejunum.

further specimens, 13 of which are between 18 and 22 weeks and the results are summarised in Table 1. In seven specimens between 11 and 17 weeks the epithelium was HLA-DR - although there were numerous HLA-DR + cells in the lamina propria (Fig. 1a). In nine specimens aged between 18 and 21 weeks, one was HLA-DR-, six had weak HLADR expression at the villus tips (Fig. 1b) and two had HLA-DR expression on most of the villus epithelial cells (Fig. 1c). Four 22 week-old specimens were studied, two of which showed strong HLA-DR expression on most of the villus enterocytes. In one specimen the epithelium was HLA-DR - in ileum and jejunum, and in the other the epithelium was HLA-DR + at the villus tips.

In those specimens in which most of the villus epithelial cells were HLA-DR +, the distribution of staining was similar to that described for adult gut, namely negative or weakly positive staining at the bases of the villi, with increasing intensity further up the villus.'

In all of the specimens examined, including the 22 week old fetal gut in which epithelial HLA-DR expression was strong, the crypt epithelium was HLA-DR - . The epithelium overlying the Peyer's patches in the older specimens (which could be easily visualised because of the intense HLA-DR staining 


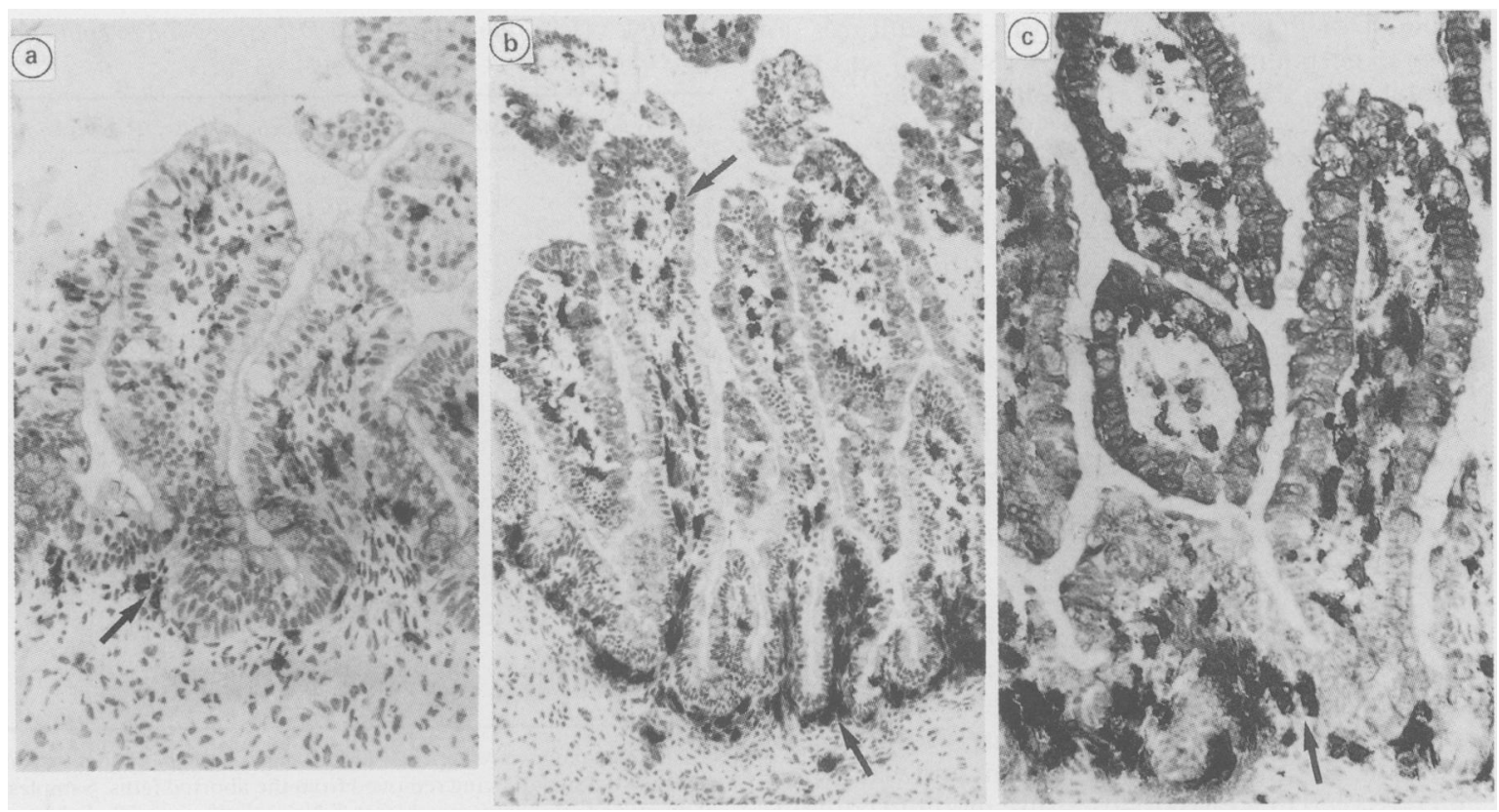

Fig. 1 The expression of $H L A-D R$ on the villus epithelium of fetal intestine aged 14 weeks $(a), 18$ weeks $(b)$, and 22 weeks (c). Note in each specimen that there are strongly $H L A-D R+$ cells in the lamina propria (arrowed), but that the $H L A-D R$ expression on the epithelium varies from none (a), to the villus tips (b, arrowed), and to most of the villus epithelial cells (c). Immunoperoxidase. Original magnification $\times 70$.

of the follicles) was also weakly HLA-DR+ in the dome region (Fig. 2).

INDUCTION OF HLA-DR EXPRESSION ON FETAL

SMALLINTESTINAL EPITHELIUM AS A

CONSEQUENCE OF MUCOSAL T CELL ACTIVATION In fetal small intestine aged 16-22 weeks there are numerous $T$ cells in the lamina propria which can be activated with mitogens in organ culture to produce villus atrophy and an increase in the rate of cell division in the crypts of Lieberkühn. ${ }^{9}$ We thus investigated whether in organ culture of fetal small intestinal explants, if $T$ cell activation resulted in increased epithelial HLA-DR expression. We chose to study fetal intestine in which HLA-DR expression was either very low or absent from the villus enterocytes at the onset of culture to help avoid the problems of quantifying changes in HLA-DR expression by immunohistochemistry.

One 17 week-old, two 18 week-old, and one 22week-old specimen were studied with the same results. In control organ cultures after three days the villus epithelium was HLA-DR - or had weak expression at the villus tips (Fig. 3a). In contrast, in cultures to which PWM was added to activate the mucosal $T$ cells, patches of the villus epithelium became strongly HLA-DR + after three days of culture (Fig. 3b). These results are summarised in Table 2. In addition the crypt epithelium also became HLA-DR+ (insert on Fig. 3b).

Previous studies have shown that the addition of PWM to cultures of 14 week-old intestinal explants, which contain few $\mathrm{T}$ cells, does not produce any mucosal changes. ${ }^{9}$ Likewise in older specimens which contain T cells, inhibition of PWM-induced mucosal $\mathrm{T}$ cell activation by Cyclosporin A prevents the

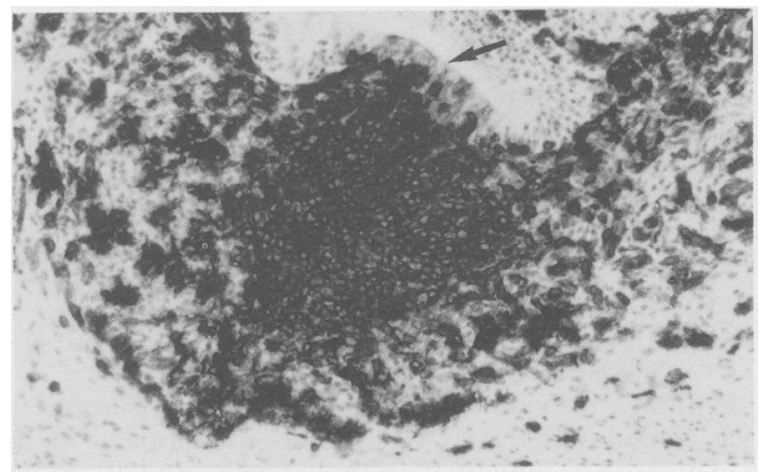

Fig. $2 H L A-D R$ expression by the Peyer's patch epithelium (arrowed) in a 22 week old fetus. Note the densely $H L A-D R+$ follicle underlying the $H L A-D R+$ epithelium. Immunoperoxidase. Original magnification $\times 70$. 
development of morphologic changes. ${ }^{9}$ In both of these experimental situations the epithelium also remained HLA-DR - .

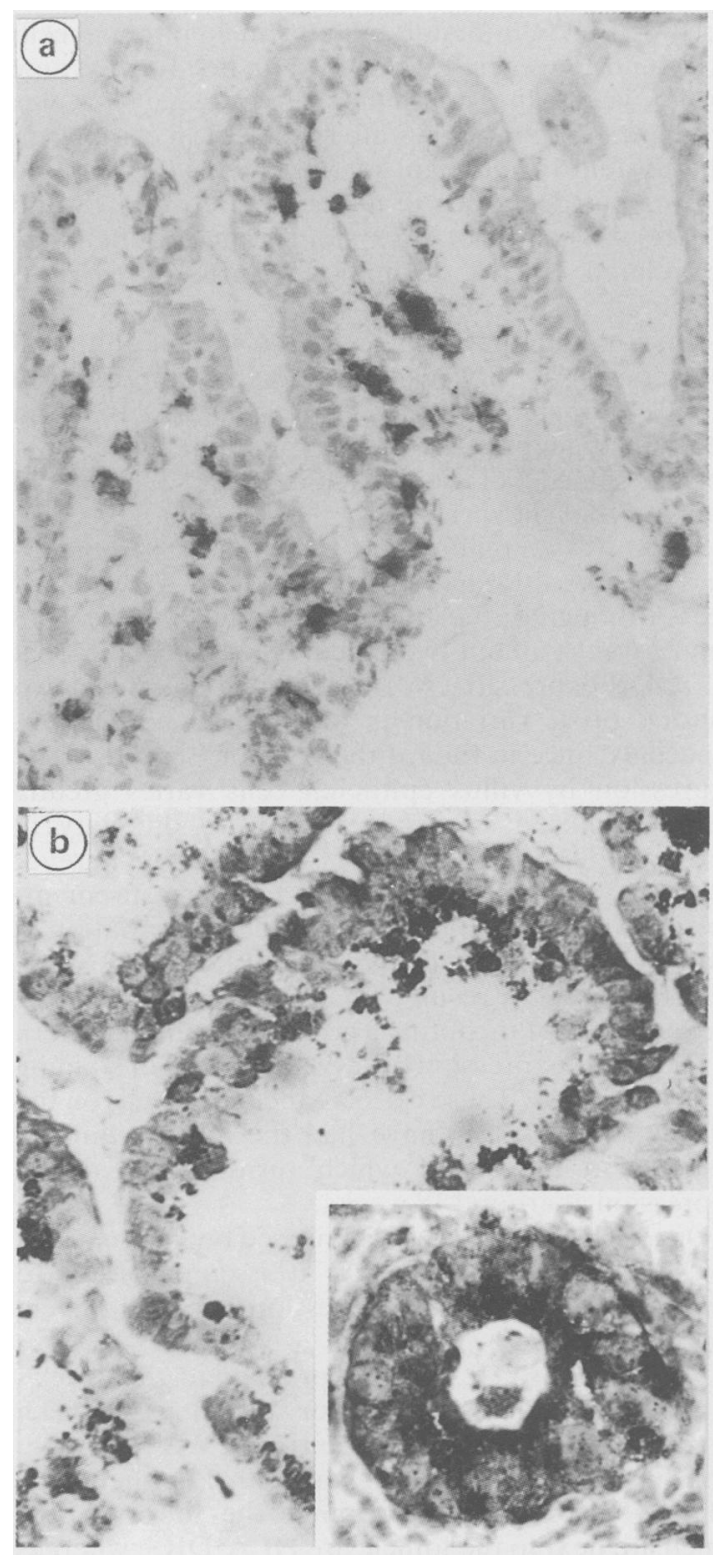

Fig. 3 HLA-DR expression in 17 week old fetal small intestinal epithelium in organ culture. In control cultures after 3 days the epithelium is $H L A-D R-(a)$. In cultures in which mucosal T cells have been activated with PWM (b), the villus epithelium and the crypt epithelium become $H L A-D R+$ (insert). Transverse sections of both villus and crypt epithelium are shown. Immunoperoxidase. Original magnification $\times 70$, insert $\times 175$.
Table 2 Activation of mucosal T cells increases $H L A-D R$ expression in epithelial cells in human small intestine organ culture in vitro

\begin{tabular}{lllll}
\hline \multicolumn{5}{c}{ HLA-DR Expression } \\
\cline { 2 - 4 } Age & Day 0 & $\begin{array}{l}\text { Control } \\
\text { cultures }\end{array}$ & $\begin{array}{l}\text { PWM-treated } \\
\text { cultures }\end{array}$ & Time in culture \\
\hline 17 weeks & - & - & ++ & 3 days \\
18 weeks & \pm & \pm & + & 4 days \\
18 weeks & \pm & \pm & + & 3 days \\
22 weeks & - & - & ++ & 3 days \\
\hline
\end{tabular}

- no HLA-DR expression in villus epithelial cells: \pm weakly positive HLA-DR + cells confined to villus tips: + most epithelial cells on the villi are weakly HLA-DR + + + very strongly HLA-DR + cells on most of the villi.

ORGAN CULTURE SUPERNATANTS FROM PWM-

TREATED SMALL INTESTINAL EXPLANTS INDUCE HLR-DR ON THE HT-29 EPITHELIAL CELL LINE

Less than $1 \%$ HT-29 cells cultured in medium alone were HLA-DR+. Treatment with interferon gamma, however, increased the number of HLADR + cells to $18 \%$ (Fig. 4). This effect titrated out with decreasing amounts of gamma interferon and was completely inhibited by sheep antigamma interferon. Organ culture supernatants from PWMtreated explants (but not control cultures) also increased HLA-DR positivity on the HT-29 cells, and this effect was also inhibited with sheep antiinterferon gamma. Recombinant interferon gamma added to the organ cultures over a wide dose range did not induce HLA-DR expression on crypt epithelial cells nor did it cause increased HLA-DR expression on the villus enterocytes (dose range 1-800 U/ml, six experiments, explants cultured for three to seven days).

\section{Discussion}

This is the first detailed description of the distribution and development of HLA-DR expression by epithelium in fetal human intestine. In agreement with our earlier work, villus epithelium was HLADR - until 17 weeks gestation. ${ }^{14}$ We had previously studied a single 19 week-old fetal intestine in which the epithelium was HLA-DR.$-{ }^{14}$ It is now clear that HLA-DR - negative specimens in this age range are in the minority because most of the specimens examined in this present study were HLA-DR+, either on most of the villus or at the villus tips. The signal which induces HLA-DR on villus epithelial cells at or around 18 weeks gestation is unknown. In the rat, Class II MHC antigen expression by villus enterocytes does not appear until about four weeks after birth, at which time the gut is infiltrated with 


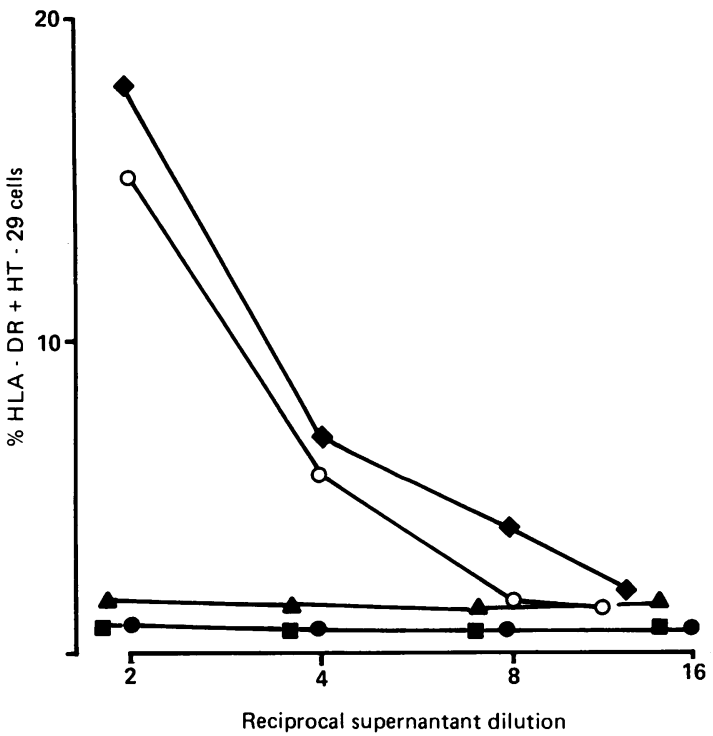

Fig. 4 The induction of HLA-DR on HT-29 cells with recombinant gamma interferon and organ culture supernatants. Each point is the mean of duplicate observations per dilution of culture supernatant or recombinant interferon gamma. In this representative experiment recombinant gamma interferon $(200$ units $/ \mathrm{ml}$, was titrated out and gave a dose dependent increase in HT-29 HLA-DR expression. Organ culture supernatants $\left(\mathrm{O}_{-}-\mathrm{O}\right)$ from explant cultures of a 22 week old fetal gut cultured for three days with PWM also caused an increase in HLA-DR expression. Control supernatants not stimulated with PWM (-) had no effect on $H L A-D R$ expression. In the presence of sheep anti-interferon gamma (final dilution in the wells-1:200) the HLA-DR inducing effects of recombinant interferon gamma ( - $\mathbf{\square})$ and the $P W M$ treated organ culture supernatant $(\mathbf{\Delta}-\mathbf{\Delta})$ was completely neutralised. Similar results have been obtained in four other experiments.

lymphocytes. ${ }^{15}$ As athymic rats have the same pattern of Class II MHC staining on the villi as normal rats ${ }^{16}$ it is unlikely, however, that $\mathrm{T}$ cells are responsible for the appearance of Class II MHC expression in rat gut. In human intestine, $T$ cells populate the gut from 14 weeks gestation,? well before the appearance of HLA-DR, thus making it also unlikely that the appearance of HLA-DR at 18 weeks is immune mediated.

An alternative notion is that HLA-DR expression may be hormonally regulated as is the case for mammary epithelium. ${ }^{17}$ It is known that the levels of epithelial cell brush border disaccharidases can be developmentally regulated by hormones. Hydrocortisone for example can increase the levels of brush border lactase when added to human fetal gut cultured in vitro. ${ }^{18}$ In some preliminary experiments we have attempted to modulate HLA-DR expression on villus epithelial cells in organ culture using hydrocortisone but have been unsuccessful.

Ultrastructural changes have, however, been documented in human fetal intestinal epithelial cells at around 18 weeks. ${ }^{19}$ When the villi first form at nine to 10 weeks the epithelial cells have a complex tubular membranous system in the apical cytoplasm. This system is abundant in cells of 15-17 week-old fetuses but decreases dramatically between 18 and 22 weeks. The role of this system is unclear but it may be related to the formation of the microvillus membrane.

It is unlikely that changes in the rate of epithelial cell renewal at 18 weeks gestation are important in the development of HLA-DR because using an antibody to identify dividing crypt epithelial cells ${ }^{4}$ we find the same levels of division in 14 and 22 week old fetal gut (not shown).

There was a great deal of variation in the appearance of HLA-DR on the villi between 18-22 weeks of age. Although of the 13 specimens aged between 18 and 22 weeks all but two had at least some epithelial HLA-DR expression. We would attribute this to two factors. First, variation in an outbred population, especially since in the rat the level of Class II MHC expression by villus epithelial cells varies greatly between inbred strains. ${ }^{16}$ Second, to difficulty in determining the exact age of the fetus. Wherever possible this was estimated by foot measurement, however, it is possible that the apparent variation in the development of HLA-DR in the 18-22 week period may be the result of inaccuracy in determining the exact age of the fetus. The most common pattern of HLA-DR expression observed was that of staining at the villus tips. These cells are the oldest cells on the villi and presumably have had the longest time to respond to the signal which turns on HLA-DR expression at around 18 weeks.

Once HLA-DR has been switched on in fetal villus epithelial cells we feel that it is appropriate to consider that HLA-DR expression is constitutively expressed by these cells.

There was also HLA-DR expression on the Peyer's patch epithelium in those older specimens in which Peyer's patches could be identified. We have previously shown that adult Peyer's patch epithelium is HLA-DR + but more interestingly that the crypt cells which are next to the follicle are HLA-DR+ whereas those on the other side of the crypt are HLA-DR $-{ }^{3}$ We postulated that this is the consequence of local $T$ cell reactions in the follicles and thus we might have predicted that fetal Peyer's patch epithelium would be HLA-DR - . The HLA-DR positivity of epithelial cells at the top of the dome, however, suggests that as these cells migrate over the follicle they mature and 
express HLA-DR in the same way as villus epithelial cells moving from the crypts onto the surface of the villus.

The other major finding of this study was that local $T$ cell activation in explants of fetal intestine in organ culture resulted in increased HLA-DR expression on epithelial cells as well as the dramatic changes in mucosal morphology described elsewhere." Intestinal inflammation as a result of gastritis, ${ }^{20}$ parasitic worm infection,"1 graft-versus-host disease, $2=$ coeliac disease, ${ }^{5}$ autoimmune enteropathy, ${ }^{, 3}$ Crohn's disease and ulcerative colitish are all associated with increased epithelial HLA-DR expression. Interferon gamma causes increased HLA-DR expression on intestinal epithelial cell lines in vitro,,$^{2+}$ a result we have confirmed here, and it is widely assumed that activated mucosal $\mathrm{T}$ cells increase epithelial HLA-DR expression by releasing interferon gamma. Consistent with this notion we found that the organ culture supernatants of explants treated with PWM could increase HLA-DR expression on HT-29 cells. This effect was neutralised with an antibody raised against recombinant human interferon gamma. Even although interferon gamma on its own can cause increased HLA-DR expression on HT-29 cells and interferon gamma can be detected in the organ culture supernatants we are unwilling to assume that interferon gamma on its own is the mediator responsible for increasing HLA-DR on intestinal epithelium in vivo. We were unable to induce or increase epithelial HLA-DR expression by the addition of large amounts of recombinant gamma interferon to explant cultures of fetal gut. Although one must be cautious in interpreting negative data, there is the possibility that interferon may not be the sole mediator causing increased HLA-DR expression in intestinal inflammation in vivo. Of relevance are the recent findings that interferon gamma and tumour necrosis factors alpha and beta synergise to increase HLA-DR expression on epithelial cells in human pancreatic epithelium. ${ }^{25}$ Studies are ongoing to determine if this is also the case in intestinal epithelium.

This work was supported by the Wellcome Trust (TTM) and The Medical Research Council (JS). Allison Weinel was a sandwich student from North East London Polytechnic supported by a grant from Crohn's in Childhood Research Appeal.

\section{References}

1 Scott H, Solheim BG, Brandzaeg P. Thorsby E. HLADR-like antigens in the epithelium of the human small intestine. Scand J Immunol 1980; 12: 77-82.

2 Natali PG, DeMartino C, Quaranta V, et al. Expression of Ia-like antigens in normal human nonlymphoid tissues. Transplantation 1981; 31: 75-8.
3 Spencer JM, Finn T. Isaacson PG. Expression of HLADR antigens on epithelium associated with lymphoid tissue in the human gastrointestinal tract. Gut 1986; 27: 153-7.

4 Bland PW, Warren LG. Antigen presentation by epithelial cells of the rat small intestine. 1. Kinetics, antigen specificity and blocking by anti-Ia antisera. Immunology 1986; 58: 1-7.

5 Arato A. Savilahti E, Taenio V-M. Verkasalo M, Klemola T. HLA-DR expression, natural killer cells and IgE containing cells in the jejunal mucosa of cocliac children. Gut 1987; 28: 988-94.

6 Selby WS, Janossy G, Mason DY, Jewell DP. Expression of HLA-DR antigens by colonic epithelium in inflammatory bowel disease. Clin Exp Immunol 1983; 53: $614-8$.

7 Spencer JM, Dillon SB, Isaacson PG, MacDonald TT. T cell subclasses in human fetal ileum. Clin Exp Immunol 1986; 65: 553-8.

8 Spencer JM, MacDonald TT, Finn TT, Isaacson PG. Development of Peyer's patches in human fetal terminal ileum. Clin Exp Immunol 1986; 64: 536-43.

9 MacDonald TT, Spencer JM. Evidence that activated T cells play a role in the development of enteropathy in human small intestine. J Exp Med 1988; 167: 1341-9.

10 Boving BG. Outline of prenatal development. In: Falkner F, ed. Human development. Philadelphia: WB Saunders, 1966: 604-19.

11 Autrup H, Barrett LA, Jackson FE,et al. Explant culture of human colon. Gastroenterology 1978; 74: 1248-57.

12 Menard D, Arsenault P. Explant culture of human fetal small intestine. Gastroenterology 1985; 88: 691-700.

13 Isaacson PG, Wright DH. Immunocytochemistry of lymphoreticular tumours. In: Polak J, van Noorden S, eds. Immunocytochemistry. Practical applications in pathology and biology. Bristol: John Wright, 1983: 249.

14 Spencer J, MacDonald TT, Isaacson PG. Heterogeneity of non-lymphoid cells expressing HLA-D region antigens in human fetal gut. Clin Exp Immunol 1987; 67: 415-24.

15 Cerf-Bensussan N, Quaroni A, Kurnick JT, Bhan AK. Intracpithelial lymphocytes modulate Ia expression by intestinal epithelial cells. J Immunol 1984; 132: 2244-52.

16 Mayrhofer G, Pugh CW, Barclay AN. The distribution. ontogeny and origin in the rat of Ia-positive cells with dendritic morphology and of la antigen in epithelia, with special reference to the intestine. Eur J Immunol 1983; 13: 112-22.

17 Klareskog L, Forsum U, Peterson PA. Hormonal regulation of the expression of la antigens on mammary gland epithelium. Eur J Immunol 1980; 10: 958-63.

18 Arsenault P, Menard D. Influence of hydrocortisone on human fetal small intestine in organ culture. $J$ Pediatr Gastroenterol Nutr 1985; 4: 893-901.

19 Moxey PC, Trier JS. Development of villus absorptive cells in the human fetal small intestine: A morphologic and morphometric study. Anat Rec 1979; 195: 463-82.

20 Spencer JM. Pugh S, Isaacson PG. HLA-D region antigen expression on stomach epithelium in absence of autoantibodies [Letter]. Lancet 1986; 2: 983.

21 Barclay AN, Mason DW. Induction of Ia antigen in rat 
epidermal cells and gut epithelium by immunologic stimuli. J Exp Med 1982; 156: 1665-76.

22 Mason DW, Dallman M. Barclay AN. Graft-versushost disease induces expression of Ia antigen in rat epidermal cells and gut epithelium. Nature 1981; 293: $150-1$.

23 Mirakian R, Richardson A, Milla PJ, et al. Protracted diarrhoea of infancy: evidence in support of an autoimmune variant. Br Med J 1986; 293: 1132-6.
24 Sollid LM, Kvale D, Brandzaeg P, Markussen G, Thorsby E. Interferon- $\gamma$ enhances expression of secretory component, the epithelial receptor for polymeric immunoglobulins. J Immunol 1987; 138: 4303-6.

25 Pujol-Borrell R, Todd I, Doshi M, et al. HLA Class 11 induction in human islet cells by interferon- $\gamma$ plus tumor necrosis factor or lymphotoxin. Nature 1987; 326: 304-6. 